ISSN 0103-5150

Fisioter. Mov., Curitiba, v. 30, n. 3, p. 537-547, Jul./Sep. 2017

Licenciado sob uma Licença Creative Commons

DOI: http://dx.doi.org/10.1590/1980-5918.030.003.A012

\title{
Spastic diparetic does not directly affect the capacity to ascend and descend access ramps: three-dimensional analysis
}

\author{
Diparesia espástica não afeta a capacidade de subir e \\ descer rampas de acesso: análise tridimensional
}

\author{
Tainá Ribas Mélo ${ }^{[a, b]}$, Ana Tereza Bittencourt Guimarães ${ }^{[c]}$, Vera Lúcia Israel ${ }^{[a] *}$ \\ [a] Universidade Federal do Paraná (UFPR), Curitiba, PR, Brazi \\ [b] Scholarship holder REUNI/Ministry of Education and Culture, Brazil \\ [c] Universidade Estadual do Oeste do Paraná (UNIOESTE), Cascavel, PR, Brazil
}

\begin{abstract}
Introduction: Diplegic children have difficulties in gait and therefore ramps are used as strategies of accessibility. Objective: The present study investigated the influence of an inclined surface (ascending and descending) on the kinematic characteristics during gait of the diplegic group (DG) when compared to typically developing children of the control group (CG). Methods: Study participants included 20 children (10 with DG and $10 \mathrm{CG}$ ) matched by age, which were evaluated in three experimental conditions (horizontal and inclined ascending and inclined descending surfaces of $7^{\circ}$ ) through an optoelectronic imaging system. Results: Among the linear kinematic variables, only step width differed among groups, however, without influence of the surface. The foot height differed among the groups only in the descending phase, where DG had greater difficulty in raising the foot. The 3-dimensional gait analyses could not provide more evidences of differences in kinematics variables, especially in transverse plane, between DG and CG, but provide some evidence to support that hip range of motion (ROM) during the gait cycle, hip flexion-extension in initial contact, knee ROM and the 2nd anterior-posterior trunk peak amplitude of the DG were influenced on descent by their flexor pattern. Conclusion: The DG was most affected by the inclination plane than CG especially on descent. Although a hip
\end{abstract}

TRM: PhD student, e-mail: ribasmelo@gmail.com ATBG: PhD, e-mail: anatbguimaraes@gmail.com

VLI: PhD, e-mail: veral.israel@gmail.com 
and knee flexor pattern is evident for DG on inclination of 7으, this angle is accessible since it allows independent gait functional activity.

Keywords: Cerebral Palsy. Diplegia. Gait. Accessibility.

\section{Resumo}

Introdução: Crianças com diplegia apresentam dificuldades na marcha e rampas são utilizadas como estratégia de acessibilidade. Objetivo: O presente estudo investigou a influência da superfície inclinada (subida e descida) sobre as variáveis cinemáticas durante a marcha no grupo com diplegia (GD) comparado ao grupo de crianças com desenvolvimento típico no grupo controle (GC). Métodos: Participaram do estudo 20 crianças (10 GD e 10 GC) pareadas por idade, as quais foram avaliadas em 3 condições experimentais (horizontal, subida e descida de $7^{\circ}$ ) por meio de um sistema de imagem optoeletrônico. Resultados: Nas variáveis cinemáticas lineares apenas o comprimento do passo diferiu entre os grupos sem influência da inclinação do plano. A altura do pé diferiu entre os grupos na descida, com maior dificuldade do GD em elevar o pé. A análise tridimensional da marcha não permitiu identificar diferenças cinemáticas no plano transverso entre GD e GC, mas identificou que a ADM de quadril durante o ciclo de marcha, flexo-extensão de joelho no contato inicial, ADM de joelho e o $2^{\circ}$ pico de amplitude de movimento (ADM) ântero-posterior de tronco do GD foram influenciadas na descida devido ao padrão flexor desse grupo. Conclusão: $O$ GD foi mais afetado que o GC, especialmente na descida. Embora sejam evidenciados padrões de flexão de quadril e joelhos do GD na inclinação de 7ํo, essa angulação é acessível ao permitir marcha funcional independente.

Palavras-chave: Paralisia Cerebral. Diplegia. Marcha. Acessibilidade.

\section{Introduction}

Gait is a complex motor task closely related to functional independence, which requires continuous adjustments of the lower limbs (LL) to accommodate environmental challenges such as obstacles and uneven surfaces (1). Walking in challenging environments poses a treat for healthy young and old controls and may represent an additional demand in subjects with motor and sensorial deficits or disabilities (2).

Cerebral palsy (CP) is a non-progressive neurological condition that can cause sensory, cognitive, perceptual disorders with implications for functional performance, especially in diparesis or diparetic/ diplegic CP (3). These children generally adopted different walking strategies, most of them with crouched gait, knee internal rotation, anterior pelvic tilt (4) with toe-walking (5). These individuals' necessities of accessibility structures that not always were investigated about yours biomechanics advantages, and the motion effectiveness.
Ramps have been recommended in order to promote accessibility for individuals with physical impairments when level changes are required (2), and in an ecological approach (6) could be an additional challenge while walking in ramps.

Thus, gait's kinematic variables have been studies while transposing inclined surfaces in subjects with typical development (7). However, only one study have analyzed the kinematic characteristics of children with cerebral palsy with increased spasticity on an inclined surface. Sott et al. (2) found that diplegic CP with Gross Motor Function Measure (GMFM) level II adapt to ramps similarly to typically development children, on sagittal plane of movement, but use greater postural adaptations, and suggest that their 2-dimensional gait analyses could be a limitation, cause they did not consider any variables in the transverse plane. A gait analyses incorporating gait parameters in all three anatomical planes can improve the evaluation of particular gait problems (8) related to diplegic children, especially in transverse plane. 
Thus, the purpose of this study was to investigate the influence of the inclined surface (ascending and descending) on the 3D gait's kinematic characteristics in children with spastic diplegic CP. In addition, diplegic subjects were compared to a control group with typically development (TD). It was hypothesized that: (1) 3-dimensional gait analyses could provide more evidences of differences in kinematics variables between DG and CG, especially in transverse plane; (2) the flexor pattern and the restrict foot strike accommodation of diplegic children could provide more difficulties and adaptations than the CG ascending and descending surfaces, mainly in angular variables on descending; (3) diplegic children could not have the same slope walking strategies that children with TD.

\section{Materials and methods}

\section{Sampling design}

This project was approved by the Research Ethics Committee of the Health Sciences Sector/ UFPR, registration CEP/SD: 936.061.10.06, CAAE: 0037.0.091.000-10. The study was conducted after consent from the legal representative, stated in the Term of Free and Informed Consent.

The sample size was calculated in GPower $3.19^{\circledR}$, assuming a 0.84 power analysis, effect size 0.80 , and type I error of 0.05 , defining a $n=20$ children. The authors Stott et al. (2) used a sample of similar size.

Figure 1 shows the experimental design of the study, described below.

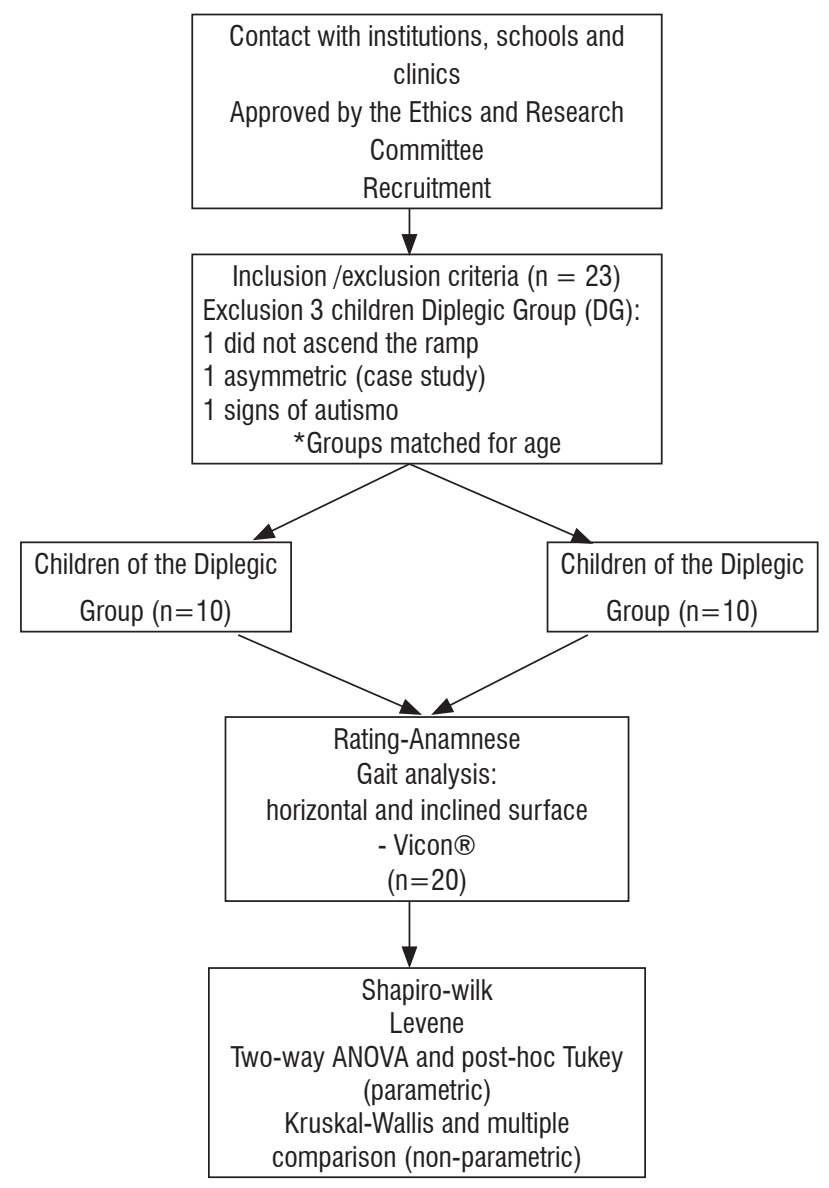

Figure 1- Study experimental design (Strobe).

Children 7-13 years were selected from regular schools, institutions and/or clinical care units. Ten children were allocated for convenience in the diplegic group $(D G=10.25 \pm 1.76$ years; $28.95 \pm 5.39 \mathrm{~kg}$;
$1.34 \pm 0.09 \mathrm{~m})$ and 10 children in the control group $(\mathrm{CG}=10.43 \pm 1.86$ years, $31.50 \pm 5.37 \mathrm{~kg} ; 1.40 \pm 0.12$ m) matched by age. 
Included in the DG were children with symmetrical independent gait with Gross Motor Function Classification System (GMFCS) I and II and that could understand simple verbal instructions $(9,10)$. The children with GMFCS II of this study did not need aids to walk on ramp. Exclusion criteria for the DG included: visual changes and/or moderate to severe intellectual disability, other CP motor disorders such as ataxia, athetosis and dystonia, orthopedic disorders such as lower limb (LL) discrepancy, shortening and deformity or other situations that could prevent independent gait (11) and symmetry, application of botulinum toxin in the LL within the previous six months (12) and phenol within a time period of less than 36 months and/or surgery in the LL or trunk within a time period of less than one year $(12$ - 14).

The control group (CG) was composed of typically developing children, matched by age. For the CG, the exclusion criteria comprised of those displaying orthopedic, neuromuscular and/or cardiovascular (15) or visual impairment that could interfere with gait, and that could engage in systematic programs of physical/ sports activities besides those of regular school.

\section{Data collection}

The children were familiarized with the assessment's climatized location and asked to walk barefoot on 3 experimental conditions: horizontal $(10 \mathrm{~m}$ walkway), ascending and descending surface (inclined surface with $7^{\circ}$ ). It was verified whether the children were able to perform the task unaided, to then afterwards walk freely at a self-selected speed on the experimental conditions. The slope of the ramp was similar to that used in other studies on populations without diplegic CP (16 - 18) and with diplegic CP (2).

Data collection was performed by using six infrared cameras $\left(\operatorname{Vicon}^{\circledR}\right)$. A set of retro-reflective markers were placed by the same experimenter on the skin at strategic points of the lower limbs (LL), from an adaptation of the Helen Hayes model (19): right and left anterior-superior iliac spines and between the two posterior superior iliac spines (sacrum), on the sides of the knees aligned with the imaginary axis of the joint, on the lateral malleolus, on the sides of the thighs and legs, over the head of the second right and left metatarsal, on the posterior side of the calcaneus. A point on the trunk was added to allow analysis since children with diplegic CP may present motion compensations in this segment due to their motor difficulties and cerebral lesion (2). The coordinates were captured so that the movement could be reconstructed in 3D.

Data were filtered by Vicon ${ }^{\circledR}$ software through a low-pass Butterwortth filter with a frequency of 10 $\mathrm{Hz}$ (20). For comparison purposes between groups only the right lower limb data were used as a reference when considering symmetry between participants (15). The stride length and step width were normalized in relation to the height of each child (21).

The data were normalized temporally as a function of the gait cycle duration. Ten gait cycles were performed and the pooled average of 3 valid attempts was calculated for each experimental condition (20). Children were allowed to rest at any time to minimize the fatigue effects (15).

\section{Data analysis}

The data were analyzed with descriptive statistics (mean and standard deviation). Shapiro-Wilk and Levene tests tested the distribution normality and homogeneity of variances respectively. Data with normal distribution were treated with parametric statistics: Student t test for independent samples was used to compare the characteristics of the subjects (weight, height and age); Two-way ANOVA was used to compare the linear and angular kinematic data having as independent factors the groups (DG and CG) and experimental conditions (horizontal, ascending and descending surface). Tukey test for equal n's was used to identify significant differences between means. The data with non-normal distribution were analyzed using the Kruskal-Wallis test, with Dunn Multiple Comparison test. Statistical tests were performed in Statistica ${ }^{\circledR}$ software adopting a significance level of $\mathrm{p} \leq 0.05$.

\section{Results}

\section{Spatial and Temporal Linear Variables}

Only the stride length differed between the groups being lower for the DG during ascent ( $p<0.05$ ). Negative values on foot elevation on ascent for the DG indicate that subjects drag the foot during the gait (Table 1). 
Table 1 - Gait spatial and temporal linear variables (mean) of children with spastic diplegic (DG) and control group (CG) during horizontal, ascent and descent surface

\begin{tabular}{|c|c|c|c|c|c|c|c|c|c|}
\hline & \multicolumn{3}{|c|}{ Horizontal } & \multicolumn{3}{|c|}{ Ascent } & \multicolumn{3}{|c|}{ Descent } \\
\hline & $D G$ & $C G$ & $p$ & $\mathrm{DG}$ & CG & $p$ & $\mathrm{DG}$ & CG & $p$ \\
\hline Total time (s) & $0.98 a$ & $1.01 \mathrm{~A}$ & 0.998 & $1.04 a$ & $1.05 \mathrm{~A}$ & 1.000 & $0.95 a$ & $1.01 \mathrm{~A}$ & 0.821 \\
\hline SwT\%** & $39.60 \mathrm{a}$ & $37.90 \mathrm{~A}$ & 0.067 & $38.85 a$ & $38.15 A$ & 0.281 & $40.85 a$ & $39.10 \mathrm{~A}$ & 0.676 \\
\hline StT\%** & $60.40 a$ & $62.10 \mathrm{~A}$ & 0.067 & $61.15 a$ & $61.85 A$ & 0.281 & $59.15 a$ & $60.90 \mathrm{~A}$ & 0.676 \\
\hline Stride (m) & $0.94 a$ & $1.12 A$ & 0.233 & $0.89 a$ & $1.14 \mathrm{~A}$ & $0.004 *$ & $0.83 a$ & $1.08 \mathrm{~A}$ & 0.067 \\
\hline Stride $\% * \star$ & $69.77 a$ & 79.77A & 0.233 & $66.15 a$ & $81.38 \mathrm{~A}$ & $0.004^{*}$ & $61.63 a$ & $77.38 \mathrm{~A}$ & 0.067 \\
\hline Gait Velocity (m/s) & $0.97 a$ & $1.12 A$ & 0.464 & $0.86 a$ & $1.09 \mathrm{~A}$ & 0.061 & $0.89 a$ & $1.08 \mathrm{~A}$ & 0.269 \\
\hline Cadence (stride/min & $62.06 a$ & $60.05 A$ & 0.988 & $58.44 a$ & $57.47 \mathrm{~A}$ & 1.000 & $64.21 a$ & $59.56 \mathrm{~A}$ & 0.679 \\
\hline Contact Velocity $(\mathrm{m} / \mathrm{s})$ & $1.52 a$ & $1.15 A$ & 0.361 & $1.38 \mathrm{a}$ & $1.11 \mathrm{~A}$ & 0.722 & $1.07 a$ & $1.08 \mathrm{~A}$ & 1.000 \\
\hline Step width (m) & $0.12 a$ & $0.09 \mathrm{~A}$ & 0.503 & $0.13 a$ & $0.09 \mathrm{~A}$ & 0.395 & $0.12 a$ & $0.09 \mathrm{~A}$ & 1.000 \\
\hline Step width \% & $0.09 a$ & $0.06 A$ & 0.503 & $0.09 a$ & $0.06 \mathrm{~A}$ & 0.395 & $0.09 a$ & $0.06 \mathrm{~A}$ & 0.647 \\
\hline Foot elevation** & $0.01 a$ & $0.02 A B$ & 1.000 & $-0.01 a$ & $0.01 \mathrm{~A}$ & 0.067 & $0.02 a$ & $0.04 B$ & $0.024 *$ \\
\hline Foot elevation \%** & $1.04 a$ & $1.34 \mathrm{AB}$ & 1.000 & $-0.54 a$ & $1.04 \mathrm{~A}$ & 0.067 & $1.24 a$ & 3.10B & $0.024^{*}$ \\
\hline
\end{tabular}

Note: DG: diplegic group; CG: control group; SwT: Swing Time; StT: Stance Time; Stride\% and step width\%= normalized with respect to height; $\mathrm{SD}=$ standard deviation.

a, b- comparison between surfaces for diplegic group $(p<0.05)$

$A, B$ - comparison between surfaces for control group $(p<0.05)$

$p$-value of comparisons between groups in each surface.

${ }^{*} \mathrm{p}<0.05$

** variables with non-parametric statistics (Kruskal-Wallis, p value).

The step width was similar between the groups for the 3 conditions. The observed difference was in relation to the group, being significantly higher $(\mathrm{p}=0.004)$ for the DG when compared to the CG.

\section{Angular Variables}

Table 2 - Gait angular variables of the lower limbs and trunk (mean) of children with spastic diplegic and control group during the horizontal, ascent and descent surface

\begin{tabular}{|c|c|c|c|c|c|c|c|c|c|}
\hline & \multicolumn{3}{|c|}{ Horizontal } & \multicolumn{3}{|c|}{ Ascent } & \multicolumn{3}{|c|}{ Descent } \\
\hline & DG & CG & $p$ & DG & CG & $p$ & DG & CG & $p$ \\
\hline Hip Flex/Ext ROM & $41.24 a$ & $42.66 \mathrm{~A}$ & 0.993 & $50.85 b$ & $52.08 B$ & 0.996 & $30.52 \mathrm{c}$ & $37.60 \mathrm{~A}$ & 0.067 \\
\hline Max Flex & $34.98 \mathrm{a}$ & $26.38 \mathrm{~A}$ & 0.128 & $47.86 \mathrm{~b}$ & 37.72B & $0.044^{*}$ & $29.82 a$ & $21.84 A$ & 0.186 \\
\hline Max Ext** & $-6.26 a$ & $-16.28 A$ & 0.708 & $-2.99 a$ & $-14.36 A$ & 0.666 & $-0.70 a$ & $-15.77 A$ & $0.012^{*}$ \\
\hline Initial contact & $31.94 a$ & 23.64A & 0.161 & 44.04b & $35.08 \mathrm{~B}$ & 0.106 & $23.75 \mathrm{c}$ & $16.43 A$ & 0.277 \\
\hline Hip Abd/Ad ROM** & $13.70 \mathrm{a}$ & 13.37A & 1.000 & $13.72 a$ & $13.53 \mathrm{~A}$ & 1.000 & $14.33 a$ & $14.67 \mathrm{~A}$ & 1.000 \\
\hline Max (adduction) & $9.62 a$ & $8.16 A$ & 0.969 & $8.47 a$ & $8.84 A$ & 1.000 & $9.08 a$ & $9.81 \mathrm{~A}$ & 0.999 \\
\hline Mín (abduction) & $-4.08 a$ & $-5.21 A$ & 0.994 & $-5.26 a$ & $-4.69 \mathrm{~A}$ & 1.000 & $-5.24 a$ & $-4.86 \mathrm{~A}$ & 1.000 \\
\hline Hip RE/RI ROM & $15.57 a$ & $20.41 \mathrm{~A}$ & 0.184 & $14.20 \mathrm{a}$ & $17.83 \mathrm{~A}$ & 0.487 & $15.08 \mathrm{a}$ & $21.99 \mathrm{~A}$ & $0.016^{*}$ \\
\hline $\operatorname{Max}(\mathrm{IR})$ & $8.42 a$ & $4.73 \mathrm{~A}$ & 0.901 & $8.59 a$ & $3.69 A$ & 0.737 & $8.01 a$ & $6.43 \mathrm{~A}$ & 0.998 \\
\hline Mín (ER) & $-7.14 a$ & $-15.68 A$ & 0.225 & $-5.61 a$ & $-14.14 A$ & 0.225 & $-7.07 a$ & $-15.56 A$ & 0.230 \\
\hline Knee ROM & $36.84 a$ & 53.77A & $0.001^{*}$ & 37.85ab & 51.14A & $0.009 *$ & $41.48 b$ & $59.23 A$ & $0.000^{*}$ \\
\hline Max 2 Flex & $33.26 a$ & $15.26 \mathrm{~A}$ & $0.025^{\star}$ & $41.62 a$ & $21.90 \mathrm{~A}$ & $0.010^{*}$ & $34.50 a$ & $20.35 A$ & 0.131 \\
\hline Max 1 Flex & $53.15 a$ & $56.32 A$ & 0.978 & $55.74 a$ & $55.44 A$ & 1.000 & $60.60 a$ & $61.12 A$ & 1.000 \\
\hline Max Ext & $16.32 a$ & $2.05 A$ & 0.223 & $17.89 a$ & $4.30 \mathrm{~A}$ & 0.271 & $19.12 a$ & $1.88 \mathrm{~A}$ & 0.082 \\
\hline Initial contact** & $26.56 a$ & $3.04 \mathrm{~A}$ & $0.003^{*}$ & $37.68 a$ & $15.69 \mathrm{~A}$ & 0.297 & $23.1 \mathrm{a}$ & $5.51 A$ & 0.073 \\
\hline Ankle ROM** & $23.86 a$ & $31.93 \mathrm{~A}$ & 0.401 & $24.66 a$ & $33.35 A$ & 0.065 & $21.69 a$ & $28.44 \mathrm{~A}$ & 1.000 \\
\hline Max flex** (dorsiflexion) & $11.64 a$ & $14.24 \mathrm{~A}$ & 1.000 & $14.20 \mathrm{a}$ & $14.60 \mathrm{~A}$ & 1.000 & $8.72 a$ & $17.96 \mathrm{~A}$ & 1.000 \\
\hline Max ext (plantarflexion) & $-12.23 a$ & $-17.69 \mathrm{~A}$ & 0.674 & $-10.46 a$ & $-18.75 A$ & 0.230 & $-12.97 a$ & $-10.48 A$ & 0.984 \\
\hline Initial contact & $-1.73 a$ & $1.56 \mathrm{~A}$ & 0.896 & $0.67 a$ & 3.64A & 0.930 & $-7.27 a$ & $-2.56 \mathrm{~A}$ & 0.656 \\
\hline Alpha foot** & $4.70 \mathrm{a}$ & $27.32 \mathrm{~A}$ & $0.008^{*}$ & $-2.43 a$ & $22.98 \mathrm{~A}$ & $0.001^{*}$ & $1.73 a$ & $17.64 \mathrm{~A}$ & 0.140 \\
\hline
\end{tabular}




\begin{tabular}{|c|c|c|c|c|c|c|c|c|c|}
\hline \multirow[b]{2}{*}{ Pelvic obliquity ROM* } & \multicolumn{3}{|c|}{ Horizontal } & \multicolumn{3}{|c|}{ Ascent } & \multicolumn{3}{|c|}{ Descent } \\
\hline & $8.15 a$ & $8.91 \mathrm{~A}$ & 1.000 & $7.51 a$ & $10.38 \mathrm{~A}$ & 0.571 & $8.89 a$ & $8.16 \mathrm{~A}$ & 1.000 \\
\hline Max 1 (elevation) & $6.33 a$ & $4.81 \mathrm{~A}$ & 0.870 & $6.38 \mathrm{a}$ & $5.46 \mathrm{~A}$ & 0.984 & $3.07 a$ & $4.61 \mathrm{~A}$ & 0.864 \\
\hline MIN Max 2 (fall) & $-1.82 a$ & $-4.10 \mathrm{~A}$ & 0.323 & $-1.14 a$ & $-4.92 \mathrm{~A}$ & $0.015^{\star}$ & $-5.82 b$ & $-3.55 A$ & 0.328 \\
\hline Pelvic tilt ROM & $9.49 a$ & $3.68 \mathrm{~A}$ & $0.005^{\star}$ & $10.58 \mathrm{a}$ & $5.06 \mathrm{~A}$ & $0.009 *$ & $7.76 a$ & $6.62 A$ & 0.976 \\
\hline Max 1 (Anterior) & $10.28 a$ & $4.11 \mathrm{~A}$ & 0.395 & $14.08 \mathrm{a}$ & $5.84 \mathrm{~A}$ & 0.120 & $-1.08 b$ & $1.40 \mathrm{~A}$ & 0.970 \\
\hline $\operatorname{Max} 2$ & $10.62 a$ & $4.19 \mathrm{~A}$ & 0.313 & $14.35 a$ & $6.29 \mathrm{~A}$ & 0.113 & $0.03 b$ & $0.99 \mathrm{~A}$ & 1.000 \\
\hline Pelvis rotation $\mathrm{ROM}^{* *}$ & $17.94 a$ & $13.55 \mathrm{~A}$ & 1.000 & $17.53 a$ & $14.39 \mathrm{~A}$ & 1.000 & $17.03 a$ & $14.95 \mathrm{~A}$ & 1.000 \\
\hline $\operatorname{Max}^{\star \star} I R$ & $7.89 a$ & $6.47 \mathrm{~A}$ & 1.000 & $7.93 a$ & $6.77 \mathrm{~A}$ & 1.000 & $7.58 \mathrm{a}$ & $7.49 \mathrm{~A}$ & 1.000 \\
\hline Max ER & $-10.05 a$ & $-7.08 \mathrm{~A}$ & 0.947 & $-9.60 a$ & $-7.61 \mathrm{~A}$ & 0.991 & $-9.45 a$ & $-7.46 \mathrm{~A}$ & 0.991 \\
\hline Anterior-posterior trunk ROM & $11.87 a$ & $4.69 \mathrm{~A}$ & $0.004^{*}$ & $10.29 a$ & $6.94 \mathrm{~A}$ & 0.978 & $11.18 \mathrm{a}$ & $6.19 A$ & 0.130 \\
\hline Max1 & $25.31 a$ & $12.09 \mathrm{~A}$ & $0.012^{*}$ & $29.07 a$ & $16.10 \mathrm{~A}$ & $0.014^{*}$ & $21.06 a$ & $11.71 \mathrm{~A}$ & 0.150 \\
\hline Max2 & 23.17a & $12.24 \mathrm{~A}$ & $0.006^{*}$ & 28.73a & $16.68 \mathrm{~A}$ & $0.002^{*}$ & $20.54 a$ & $10.89 \mathrm{~A}$ & $0.022^{*}$ \\
\hline Min & 13.94ab & $7.96 \mathrm{~A}$ & 0.284 & $19.65 a$ & $10.48 \mathrm{~A}$ & $0.021^{*}$ & $11.21 \mathrm{~b}$ & $6.04 \mathrm{~A}$ & 0.442 \\
\hline
\end{tabular}

Note: DG: diplegic group; CG: control group; ROM: range of motion (in degrees `); Flex: flexion; Max: maximum; Ext: extension; Abd: abduction; Ad: adduction; IR: internal rotation; ER: external rotation. a, b- comparison between surfaces for diplegic group $(p<0.05)$. A, B- comparison between surfaces for the control group $(p<0.05)$. $p$-value of comparisons between groups in each surface.

${ }^{*} p<0.05 .{ }^{* \star}$ Variables with non-parametric statistics (Kruskal-Wallis, $p$ value).

The angular variables for lower limbs (LL) (Table 2) showed differences during the range of motion (ROM) of hip flexion and extension was influenced by the experimental conditions, but not of the group, that is, there was a change of hip flexion and extension values in the horizontal surface conditions $(41.24 \pm 5.99$ vs $42.66 \pm 4.17)$ and on ascent $(50.85$ \pm 6.83 vs $52.08 \pm 2.64$ ), both in the DG as well in the CG respectively. However, the values of maximum hip flexion during ascent were higher in the DG. On initial contact, both groups increased hip flexion during ascent and decreased during descent, with higher values for the DG than for the CG.
For hip extension the DG showed lower values in all the experimental conditions, with significant differences between the groups only on descent $(-0.70$ \pm 9.63 vs $-15.77 \pm 5.02$ )

In the transverse plane, the hip rotation amplitude in the control group (CG) was higher than in the DG during descent. In the frontal plane, no differences between groups were found for maximum hip adduction and abduction or between the experimental conditions. Figures 2 and 3 show the angular displacements (motor behavior) of both groups in the 3 experimental conditions.
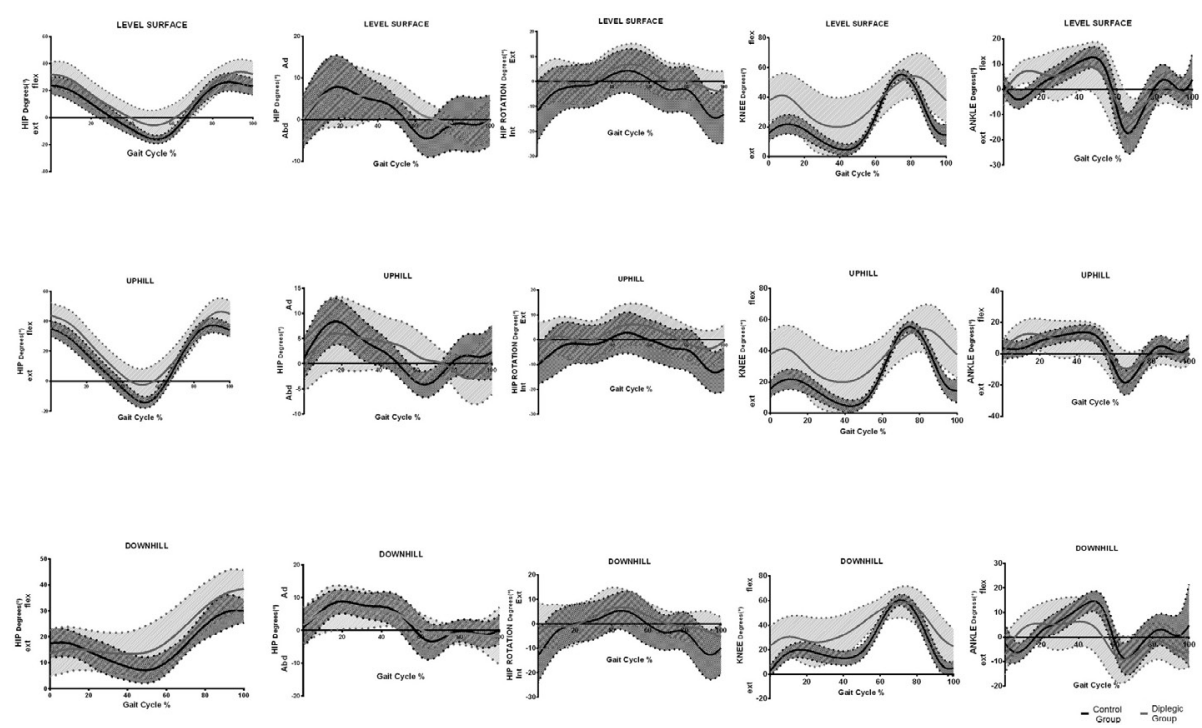

Figure 2 - Evolution of the angular variables of the hip, knee and ankle of the Control Group and Diplegic Group over time, in horizontal, ascent and descent surfaces. 

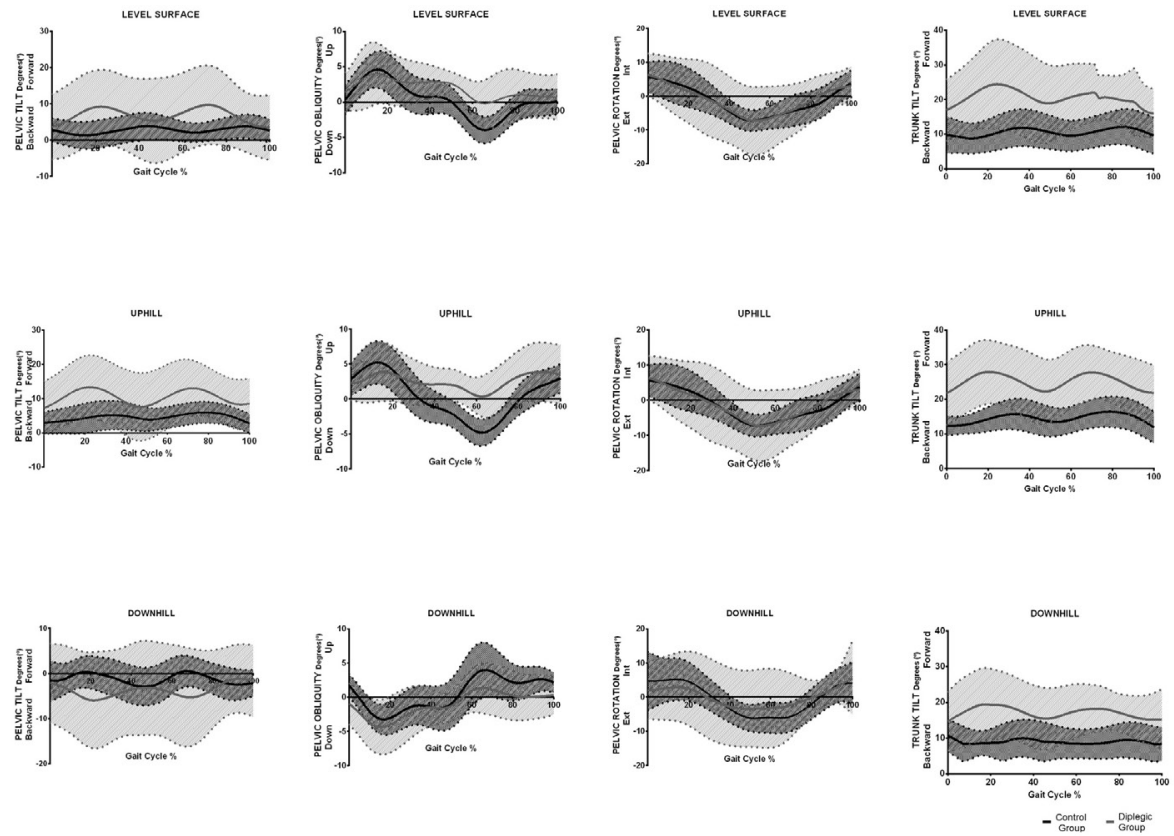

Figure 3 - Evolution of the angular variables of the pelvis and trunk Control Group and Diplegic Group over time, the horizontal, ascending and descending surfaces.

The knee ROM was lower in the DG than in the CG in all experimental conditions. On initial contact, the DG presented greater knee flexion and in the stance phase, no differences were found between groups. During the swing phase, this variable was greater for the DG compared to the CG in the horizontal and ascent surface.

For the pelvic tilt range differences were found between the DG and the CG in the horizontal and ascent surface. The differences were related to groups and not to the experimental conditions.

On the horizontal surface the DG presented greater trunk anterior tilt and higher variability in this pattern. On the ascent and descent the groups did not differ between themselves for trunk ROM. While for the $1^{\text {st }}$ and $2^{\text {nd }}$ anterior trunk tilt peaks, the DG presented greater anterior tilt, with no differences between the experimental conditions.

Pelvic obliquity and rotation did not differ between groups or conditions evaluated.

\section{Discussion}

Spatial and Temporal Linear Variables

In this study there was no difference in the stride length in the horizontal surface between the DG and CG, contrasting Carriero et al. (4) in studying children with diplegic CP $(0.80 \pm 0.26$ vs $1.16 \pm 0.16)$, without previous surgery, probably with greater muscle shortening than in the present study, that accepted children at least one year of previous surgery.

Although no significant differences were found as mentioned by Stott et al. (2) during descent, the DG had a smaller stride length tendency in the 3 experimental conditions, probably due to the subjects' motor control deficit, considering that $\mathrm{CP}$ causes changes in posture and voluntary movement execution (22) and step reduction can be a strategy (23) consequently of the brain lesions and difficulties of the movement control (2). The lack of difference among experimental conditions for both groups could be due to the low inclination $\left(7^{\circ}\right)$ which is considered within the standards for accessibility and would facilitate movement execution. This is also defended by Kawamura et al. (23) that identified changes on this variable from an inclination of 12 .

Despite the speed values $(0.97 \pm 0.22)$ and gait cycle time $(0.98 \pm 0.13)$ in the horizontal surface of the DG were similar to those found by Carriero et al. (4), in this surface those of the DG were similar to those of the CG. Carriero et al. (4) and Hsue et al. (24) reported that children with diplegic CP presented slower speed than those of typically developing children $(0.86 \pm 0.32$ vs $1.36 \pm 0.17 ; 1.34 \pm 0.29$ vs $1.71 \pm 0.43$, respectively). This due to motor control difficulty of these children and mainly related to the decrease in 
knee and peak knee flexion ROM in swing phase. In this study, this difference between the groups, when the experimental conditions of the horizontal surface to the inclined surface were not considered, differs from what was reported by Stott et al. (2).

In evaluating the step width the DG showed higher values than the CG in the 3 conditions, as a strategy to improve the base of support and their center of mass displacement difficulties $(24,25)$. The experimental conditions did not influence this variable, which corroborates with other studies (23).

The differences between this study and what was reported by Stott et al. (2) may be due to the inclusion criteria. In our study, we evaluated children of level I and II of the GMFCS and the other authors assessed children only from level II; also the difference may be due to the type of motion analysis, this research used three-dimensional analysis whereas the above authors used two-dimensional analysis.

\section{Angular Variables}

On ascent, similar to what some studies $(17,23$, 26) have observed both the DG as well as the CG increased hip flexion during gait to adjust the foot to surface inclination, from the initial contact, and this would be directly related to the degree of inclination. This strategy was observed as being influenced by the inclination surface but not by the group type, which for some researchers $(4,5)$, is due to the DG flexor pattern. This would lead to less dynamic hip extension, evidenced for the DG in the 3 conditions, with notable difference during descent.

There was no difference between the maximum hip adduction and abduction for the experimental conditions between groups, which agrees with Steinwender et al. (27) for which only in the crouched gait pattern would the diplegic child present instability to activate the hip abductors on the swing due to selective control difficulty (27). While for Carriero et al. (4), and Kirkwood et al. (28) in the horizontal surface there would be a difference in these variables for diplegic children.

For hip rotation ROM only on descent were the groups different and the CG presented higher ROM than the DG. Despite the statistical similarity of maximum external rotation between the groups, on the three inclined surfaces, it was observed that the DG always presented lower values during gait. Children with diplegic CPmay present higher maximum internal rotation values in the horizontal surface when compared to the CG (4), as a musculoskeletal adaptation to the gait's functional movement.

For knee flexion/extension ROM the DG showed lower values than the $\mathrm{CG}$, differing from each other in the 3 conditions. Hamstring tightness of children with diplegic CP can justify knee extension difficulty (4) and is therefore an effect of the group, not from surface inclination.

When evaluating initial contact in the horizontal surface the DG showed higher knee flexion values, possibly due to the flexor pattern evidenced in children with diplegic CP $(4,29)$. Even higher values were observed during ramp ascent as mentioned by Stott et al. (2).The increase on this variable is reported for typical gait (22) as well as for gait with diplegic $\mathrm{CP}$ in surface change as a neuromotor adjustment strategy to accommodate the lower member to the inclination. Maximum knee flexion occurring in the swing phase was not different between the groups on the horizontal surface, like the results of Carriero et al. (4), nor among the inclined surfaces.

The value of the maximum knee flexion in the stance phase was higher for the DG on the horizontal surface and on ascent (2), and consequently showed lower extension. Although significant differences were not observed, there was a trend of the CG to perform the extension movement, while diplegic children remain in flexion, this event is also demonstrated on the horizontal surface $(4,29)$ and inclined surface (2) due to the flexor pattern of these children.

Hyperactivity and/or shortening of the gastrocnemius muscle, which is biarticular, could have greater action on the knee joint, with increase in its flexion, than on the ankle joint (30) and this was also demonstrated in this study.

Although no significant differences have been shown in maximum ankle flexion and extension on initial contact and during the gait cycle, the DG motor behavior was atypical, in plantar flexion and with great variability, just as for Steinwender et al. (27) and Maas et al. (30) who suggest that this DG variability could explain the lack of differences between groups, as demonstrated in this study. The inclination surface did not influence the variables agreeing with studies by McIntosh et al. (17) and Leroux et al. (26) who observed differences starting from inclinations of $10^{\circ}$. 
In the analysis of foot angle relative to the surface it was found that there was inter and intra-group differences. The DG does not accommodate the foot to the surface as does the CG making contact in plantarflexion due to the difficulty of making it in dorsiflexion due to the shortened gastrocnemius muscle (30). This difficulty associated with knee flexor pattern also influenced the foot elevation variable. The negative value for ascent represents that the DG drags the foot. Even though the methodological analysis of van der Krogt et al. (31) was different, the authors also demonstrated this difficulty of raising the foot off the ground (pre-swing).

There was a pelvic tilt ROM difference between the groups on the horizontal surface and on ascent, agreeing with Carriero et al. (4) who found greater anterior pelvic tilt for children with diplegic CP. This would happen as a compensation due to the decrease in extension capability of these children $(5,32)$ and in the flexed knee gait by the gait pattern and the weakness of the extensor muscles of knee and hip joint (32). The proportional increase to the ramp's inclination would occur as a means to follow the movement and allow increased hip flexion, coinciding with simple support on each side $(17,26)$.

Regarding pelvic obliquity a difference was observed in minimum obliquity (fall) when comparing the inclination of surfaces, with a predominance of negative values between DG during descent. These findings are in agreement with other authors $(4,27)$ who explained this by the fact that children with diplegic CP present functional symmetry between the LL just as typical children. The increased pelvic obliquity would be used only as compensation for people with asymmetry (discrepancy) in the length of the LL or functional discrepancy, as in the case of hemiparetic.

There was no difference between the DG and CG in the horizontal surface for pelvic rotation. With respect to the trunk the DG has more trunk anterior displacement than the CG, like the children evaluated by Heyrman et al. (10) in the horizontal surface and by Stott et al. (2) during ascent. For these authors this may be due to postural instability of these children and as compensation of changes in the LL and pelvis. In addition, it could be compensation due to hip extensor weakness of the DG and a lack of eccentric control of the quadriceps (2). The great variability of movement shown in the DG makes the comparison between groups difficult.
It's worth mentioning that the high variability of values for all joints among children with diplegic $\mathrm{CP}$ were also observed in the study by Stott et al. (2) and lead to consider an immaturity of movements, corroborating the findings of Hodapp et al. (33) and Prosser et al. (15). Immaturity in the gait for the DG would be a consequence of encephalic lesion and inhibition of the tonic muscular development that occurs over the children's growth (33).

This variability, however, was observed in all three inclined surfaces in a similar manner.

\section{Study limitations}

Some limitations in the study were considered: 1 - The small sample size. Randomized studies with larger populations in child care centers with CP are suggested.

2 - The gait analysis in this study was not categorized by groups according to gait patterns. Studies which categorize these variables are suggested.

\section{Conclusion}

Despite the initial hypothesis that 3-dimensional gait analyses could provide more evidences of differences in kinematics variables between DG and CG, especially in transverse plane it was not observed due the great variability of movement shown in the DG.

The findings provide some evidence to support the second hypothesis and some variables were more influenced on descent by their flexor pattern. This fact occurs on foot elevation in the GC, and for the variables: hip ROM during the gait cycle; hip flexionextension in initial contact; knee ROM and the $2^{\text {nd }}$ anterior-posterior trunk peak amplitude of the DG, and therefore, being more influenced by the descent condition than by the CG. Probably on descent places high demands on the knee extensors and the excessive knee flexion seen in DG may reflect underlying poor eccentric quadriceps control, necessitating greater compensations at the trunk, hip and knee.

In conclusion we refute the third hypothesis and concluded that the inclination of $7^{\circ}$ advocated by ABNT $(34)$ and international law $(17,26)$ is adequate to ensure functional gait in children with diplegic $\mathrm{CP}$ in environments that require accessibility. 
The implications of the findings of this study provide evidence about acessibility and understanding for new investigations about the environment influences on the motor strategies of diplegic children.

\section{Acknowledgements}

The authors thank the Support Program for the Restructuring and Expansion of Federal Universities (Reuni), established by Decree № 6.096 of April 24, 2007 by the Ministry of Education and Culture (MEC) of Brazil, for granting the master's scholarship.

\section{References}

1. Figueiredo PR, Silva PL, Avelar BS, Chagas PS, Oliveira LC, Mancini MC. Assessment of gait in toddlers with normal motor development and in hemiplegic children with mild motor impairment: a validity study. Braz J Phys Ther. 2013;17(4):359-66.

2. Stott NS, Reynolds N, McNair P. Level versus inclined walking: ambulatory compensations in children with cerebral palsy under outdoor conditions. Pediatr Phys Ther. 2014;26(4):428-35.

3. Tosun A, Gökben S, Serdaroglu G, Polat M, Tekgöl H. Changing views of cerebral palsy over 35 years: the experience of a center. Turk J Pediatr. 2013;55(1):8-15.

4. Carriero A, Zavatsky A, Stebbins J, Theologis T, Shefelbine SJ. Correlation between lower limb bone morphology and gait characteristics in children with spastic diplegic cerebral palsy. J Pediatr Orthop. 2009;29(1):73-9.

5. Hicks JL, Schwartz MH, Arnold AS, Delp SL. Crouched postures reduce the capacity of muscles to extend the hip and knee during the single-limb stance phase of gait. J Biomech. 2008;41(5):960-7.

6. Ahl LE, Johansson E, Granat T, Carlberg EB. Functional therapy for children with cerebral palsy: an ecological approach. Dev Med Child Neurol. 2005;47(9):613-9.

7. Noble JW, Prentice SD. Intersegmental coordination while walking up inclined surfaces: age and ramp angle effects. Exp Brain Res. 2008;189(2):249-55.
8. Carriero A, Zavatsky A, Stebbins J, Theologis T, Shefelbine SJ. Determination of gait patterns in children with spastic diplegic cerebral palsy using principal components. Gait Posture. 2009;29(1):71-5.

9. Fowler EG, Goldberg EJ. The effect of lower extremity selective voluntary motor control on interjoint coordination during gait in children with spastic diplegic cerebral palsy. Gait Posture. 2009;29(1):102-7.

10. Heyrman L, Feys H, Molenaers G, Jaspers E, Monari D, Meyns P, et al. Three-dimensional head and trunk movement characteristics during gait in children with spastic diplegia. Gait Posture. 2013;38(4):770-6.

11. Rodda JM, Graham HK, Carson L, Galea MP, Wolfe R. Sagittal gait patterns in spastic diplegia. J Bone Joint Surg Br. 2004;86(2):251-8.

12. Wingert JR, Sinclair RJ, Dixit S, Damiano DL, Burton H. Somatosensory-evoked cortical activity in spastic diplegic cerebral palsy. Hum Brain Mapp. 2010;31(11):1772-85.

13. Eek MN, Beckung E. Walking ability is related to muscle strength in children with cerebral palsy. Gait Posture. 2008;28(3):366-71.

14. Mélo TR, Rodacki ALF, Guimarães ATB, Israel VL. Repeatability and comparison of clinical tests in children with spastic diplegia and with typical development. Fisioter Mov. 2015;28(1):13-22.

15. Prosser LA, Lauer RT, VanSant AF, Barbe MF, Lee SC. Variability and symmetry of gait in early walkers with and without bilateral cerebral palsy. Gait Posture. 2010;31(4):522-6.

16. Carriero A, Zavatsky A, Stebbins J, Theologis T, Shefelbine SJ. Determination of gait patterns in children with spastic diplegic cerebral palsy using principal components. Gait Posture. 2009;29(1):71-5.

17. McIntosh AS, Beatty KT, Dwan LN, Vickers DR. Gait dynamics on an inclined walkway. J Biomech. 2006;39(13):2491-502.

18. Prentice SD, Hasler EN, Groves JJ, Frank JS. Locomotor adaptations for changes in the slope of the walking surface. Gait Posture. 2004;20(3):255-65. 
19. Melanda AG, Kawamura CM, Freitas CD, Lucareli PRG, Pinheiro PO. Laboratório de Marcha. In: Borges D, Moura EW, Lima E, Silva PAC. Fisioterapia: aspectos clínicos e práticos da reabilitação. São Paulo: Artes Médicas; 2007. p. 615-40.

20. Hsue B-J, Miller F, Su F-C. The dynamic balance of the children with cerebral palsy and typical developing during gait. Part I: Spatial relationship between COM and COP trajectories. Gait Posture. 2009;29(3):465-70.

21. Saraph V, Zwick E-B, Auner C, Schneider F, Steinwender G, Linhart W. Gait improvement surgery in diplegic children: how long do the improvements last? J. Pediatr. Orthop. 2005;25(3):263-7.

22. Bax M, Goldstein M, Rosenbaum P, Leviton A, Paneth N, Dan B, et al. Proposed definition and classification of cerebral palsy, April 2005. Dev Med Child Neurol. 2005;47(8):571-6.

23. Kawamura K, Tokuhiro A, Takechi H. Gait analysis of slope walking: a study on step length, stride width, time factors and deviation in the center of pressure. Acta Med Okayama. 1991;45(3):179-84.

24. Hsue BJ, Miller F, Su FC. The dynamic balance of the children with cerebral palsy and typical developing during gait: Part II: Instantaneous velocity and acceleration of COM and COP and their relationship. Gait Posture. 2009;29(3):471-6.

25. Stackhouse C, Shewokis PA, Pierce SR, Smith B, McCarthy J, Tucker C. Gait initiation in children with cerebral palsy. Gait Posture. 2007;26(2):301-8.

26. Leroux A, Fung J, Barbeau H. Postural adaptation to walking on inclined surfaces: I. Normal strategies. Gait Posture. 2002;15(1):64-74.
27. Steinwender G, Saraph V, Zwick EB, Steinwender C, Linhart W. Hip locomotion mechanisms in cerebral palsy crouch gait. Gait Posture. 2001;13(2):78-85.

28. Kirkwood RN, Franco RdLLD, Furtado SC, Barela AMF, Deluzio KJ, Mancini MC. Frontal Plane motion of the pelvis and hip during gait stance discriminates children with diplegia levels I and II of the GMFCS. ISRN Pediatrics. 2012;2012: 163039.

29. Brunner R, Dreher T, Romkes J, Frigo C. Effects of plantarflexion on pelvis and lower limb kinematics. Gait Posture. 2008;28(1):150-6.

30. Maas JC, Huijing PA, Dallmeijer AJ, Harlaar J, Jaspers RT, Becher JG. Decrease in ankle-foot dorsiflexion range of motion is related to increased knee flexion during gait in children with spastic cerebral palsy. J Electromyogr Kinesiol. 2015;25(2):339-46.

31. van der Krogt MM, Bregman DJ, Wisse M, Doorenbosch CA, Harlaar J, Collins SH. How crouch gait can dynamically induce stiff-knee gait. Ann Biomed Eng. 2010;38(4):1593-606.

32. Shin HI, Sung KH, Chung CY, Lee KM, Lee SY, Lee $\mathrm{IH}$, et al. Relationships between Isometric Muscle Strength, Gait Parameters, and Gross Motor Function Measure in Patients with Cerebral Palsy. Yonsei Med J. 2016;57(1):217-24.

33. Hodapp M, Klisch C, Mall V, Vry J, Berger W, Faist M. Modulation of soleus H-reflexes during gait in children with cerebral palsy. J. Neuroph. 2007;98(6):3263-8.

34. Associação Brasileira de Normas Técnicas. Acessibilidade a edificações, mobiliário, espaços e equipamentos urbanos. ABNT NBR 950:2004. 97 p.
Received in 05/01/2016

Recebido em 01/05/2016

Approved in 02/07/2017

Aprovado em 07/02/2017 